\title{
An experimental test of three choice shift hypotheses*
}

\author{
JOHN KEITH MURNIGHAN and CARL H. CASTORE \\ Purdue University, West Lafayette, Indiana 47907
}

\begin{abstract}
The present experiment pitted three choice shift hypotheses against each other in an attempt to eliminate one or more of the hypotheses and find support for those remaining. Ss responded three times to the $12 \mathrm{CDQ}$ items, once as a pretest and twice following presentation of homogeneous sets of three arguments which advocated either a risky or a cautious position. The risk-as-value, relevant arguments, and conformity/attitude change hypotheses generated three separate predictions for the Ss' responses. Results mirrored the prediction of the relevant arguments hypothesis: New information, whether contained in cautious or risky arguments, caused a shift toward the type of argument presented. The risk-as-value and the conformity/attitude change hypotheses could not explain the present data.
\end{abstract}

Research on the risky shift (or choice shift) phenomenon has recently led to an impasse where several hypotheses have been proposed but where none stands out as the most plausible. Recently, Pruitt (1971) argued that experimental tests are needed to eliminate one or more hypotheses while presenting strong evidence for those hypotheses which remain.

The present study is an attempt to pit three recent hypotheses against each other. The risk-as-value hypothesis (Brown, 1975; Madaras \& Bem, 1968; Pruitt, 1968) states that a choice shift depends upon two assumptions: (1) Risk is valued in our culture in most situations, and (2) social comparison processes operate when a group convenes to make a decision or discuss an issue. For situations eliciting a value for risk, individuals hope to appear at least as risky as other group members. Individuals who find themselves in a group of people advocating a riskier position than their own shift toward risk, causing the average for the group as a whole to shift toward risk. For situations eliciting a value for caution, the same processes apply in the opposite direction and cause an apparent group shift toward caution. Several studies (e.g., Levinger \& Schneider, 1969; Wallach \& Wing, 1968) have supported these assumptions.

The second hypothesis, presented by Vinokur (1971), also assumes a risk as a cultural value in most situations. Instead of assuming the existence of social comparison processes, however, the relevant arguments hypothesis assumes that information in the group discussion is most often information supporting the risky alternative. This information, if it is new, contributes to a group's shift toward risk in most situations. The converse holds true in situations which elicit a value for caution.

The final hypothesis to be tested in the present experiment is the conformity/attitude change hypothesis presented by Castore and Roberts (1972). This hypothesis, borrowing from Sherif's social judgment/involvement model (Sherif, Sherif, \& Nebergall, 1965), assumes that the individual who is

\footnotetext{
*This research was supported in part by a grant from the Office of Naval Research (N00014-67-A-0226) to the second author. Requests for reprints should be sent to Carl $\mathrm{H}$. Castore. Department of Psychological Sciences, Purdue University, West Lafa yette, Indiana 47907.
}

risky is also highly committed. This individual is normally the most influential group member during the group's discussion and elicits conformity and attitude change among the other group members toward his risky position.

Figure 1 indicates the general types of individual risk preference changes which would be anticipated for choice dilemma questionnaire (CDQ) type items (Kogan \& Wallach, 1964) following exposure to a series of risky or cautious arguments under the foregoing three hypotheses. The predictions may be summarized as follows. (1) Risk-as-value hypothesis: For the risk-oriented items, groups should shift toward risk after hearing risky arguments and should not shift after hearing cautious arguments. The reverse holds for the two caution-oriented items. (2) Relevant arguments hypothesis: New information, whether contained in cautious or risky arguments, should cause a shift toward the type of argument presented. (3) Conformity/attitude change hypothesis: Both cautious and risky arguments should change the preferences of the group, with risky arguments causing a greater shift.

\section{METHOD}

\section{Subjects}

The Ss were 68 undergraduates in the introductory psychology class at a large Midwestern university. Their participation fulfilled part of a course requirement.

\section{Procedure}

Ss responded to the CDQ on a 10-point scale from 1 chance in 10 through 9 chances in 10 , including an opportunity to respond that the risky alternative should not be taken, regardless of the odds. (This response was scored as 10 chances in 10.) Following their initial responses, Ss were presented with the first set of arguments. The arguments were homogeneous with respect to the position they advocated (i.e., all risky or all cautious). Each set included three arguments presented by three different individuals. Ss were told that these arguments had been tape recorded in a previous experiment and had been selected to represent the responses of three average Ss. (Actually, the arguments had been read from a script by confederates of the E.) Each set advocated 1, 2, and 3 chances in 10 (risk arguments) or 7,8 , and 9 chances in 10 (caution arguments). Following presentation of the argument set for each item, Ss responded as to their risk preferences a second time. The final stage of the 

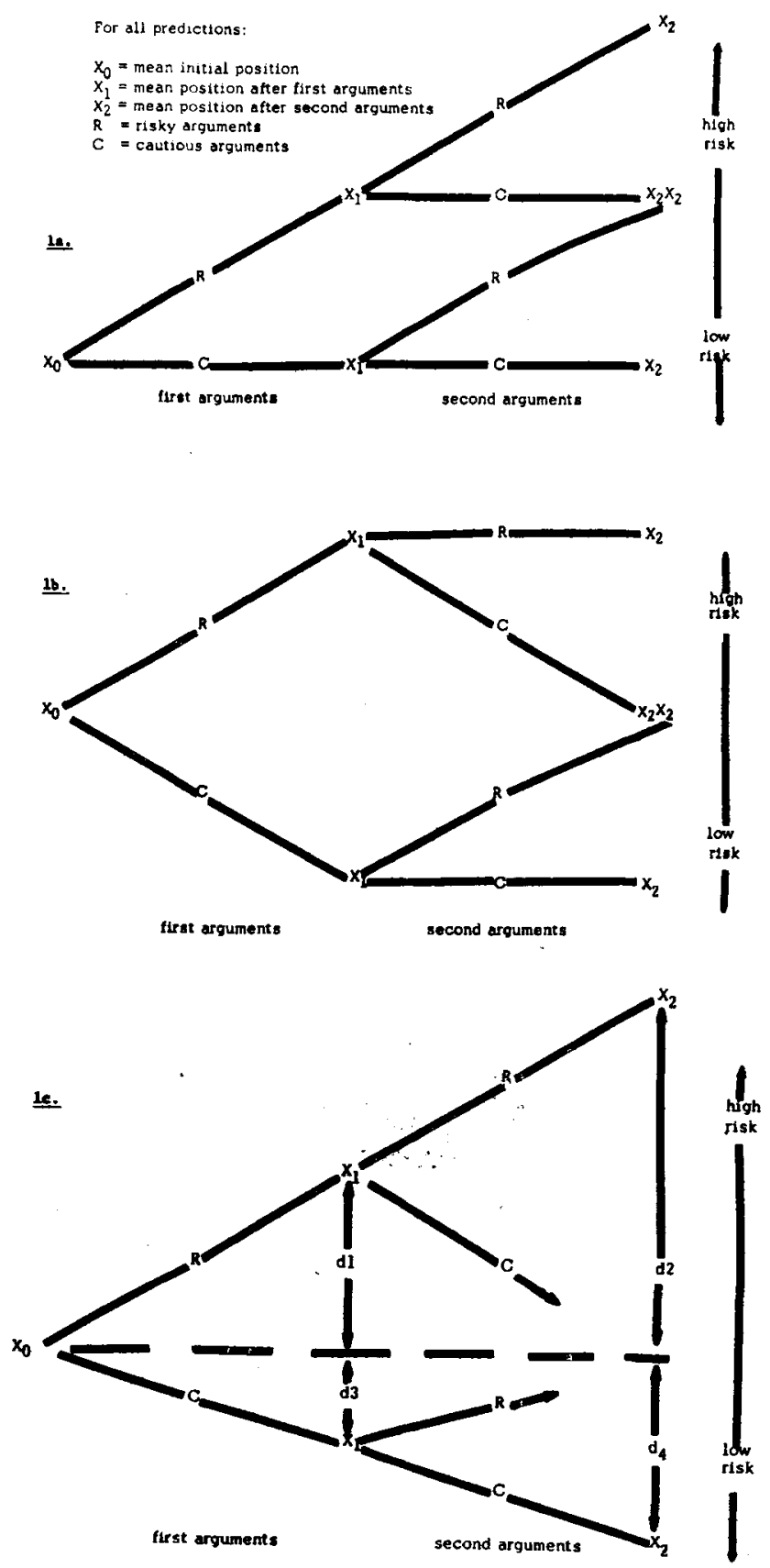

$d_{1}>d_{3}$ and $d_{2}>d_{4}$

Fig. 1. The predictions of the three hypotheses: (a) the risk-as-value hypothesis (for risk-oriented items only; the prediction for the caution-oriented items is a mirror image of this prediction); (b) the relevant arguments hypothesis; and (c) the conformity/attitude change hypothesis.

experiment duplicated the previous stage, in that a set of three homogeneous arguments was again presented to the Ss before they reevaluated their risk preferences.

\section{Design}

The arguments were presented so that each $S$ heard six risk argument sets and six caution argument sets during each phase of the experiment. Ss also received each of the four possible argument sequences (risk-risk, risk-caution, caution-risk, and caution-caution), one sequence for each of 3 of the 12 items. Each of the 12 items was paired with each of the four argument sequences for one-fourth of the Ss. The three different risk levels advocated in each argument set were randomly ordered.

For the risk-risk and the caution-caution argument sequences, the information contained in the two argument sets was the same. The second set of arguments was slightly reworded and was read by different confederates so that the arguments per se would not sound exactly the same. For the risk-caution and the caution-risk argument sequences, the information contained in each of the argument sets was different.

An example of one of the cautious arguments used for the first of the 12 items was, "Staying with his present company means security for him and his family. He will receive a good pension and a good income. I don't think Mr. A should try it unless his chances are at least 7 in 10." The other arguments were similar in length and content. Following presentation of the three arguments in each set, the Ss were requested to present an argument supporting their own current position. They were told that their responses were being tape recorded for potential use in similar experiments in the future. No such recordings were actually made; the Ss merely presented their arguments into a dead microphone.

The experiment, then, proceeded through three phases: a pretest and two posttests, each following presentation of a group of three-argument sets.

\section{RESULTS}

Three separate analyses were performed to test the predictions of the different hypotheses. An overall analysis of variance (items by arguments by trials by Ss) was performed on the Ss' risk preferences to test the predictions of the relevant arguments and the conformity/attitude change hypotheses. Two separate analyses of variance, one for the risk-oriented items and one for the caution-oriented items, were performed to test the predictions of the risk-as-value hypothesis.

The overall analysis revealed two significant main effects and two significant interactions: the items and the arguments main effects $[F(11,704)=17.11, p<.01$ and $F(3,64)=18.33, p<.01$, respectively], the Items by Trials interaction $[\mathrm{F}(22,1408)=1.78, \mathrm{p}<.05]$, and the Arguments by Trials interaction $[F(6,128)=27.51$, $\mathrm{p}<.01]$.

The significant interactions were further analyzed on a post hoc basis using the Newman-Keuls procedure (Winer, 1962). The Items by Trials interaction, which just reached significance, shows no significant differences between trials for any one item. Instead, the significant differences were found between items. [This result was not unexpected in the light of the main effect for items and national norms compiled for the items by Pruitt and Teger (1967).] Because of these differences, additional analyses were performed on each item individually. Only one item showed a nonsignificant Arguments by Trials interaction. Although the items showed different values for the first trial, the changes caused by the arguments tended to be uniform across items. In effect, then, each individual item acted very 


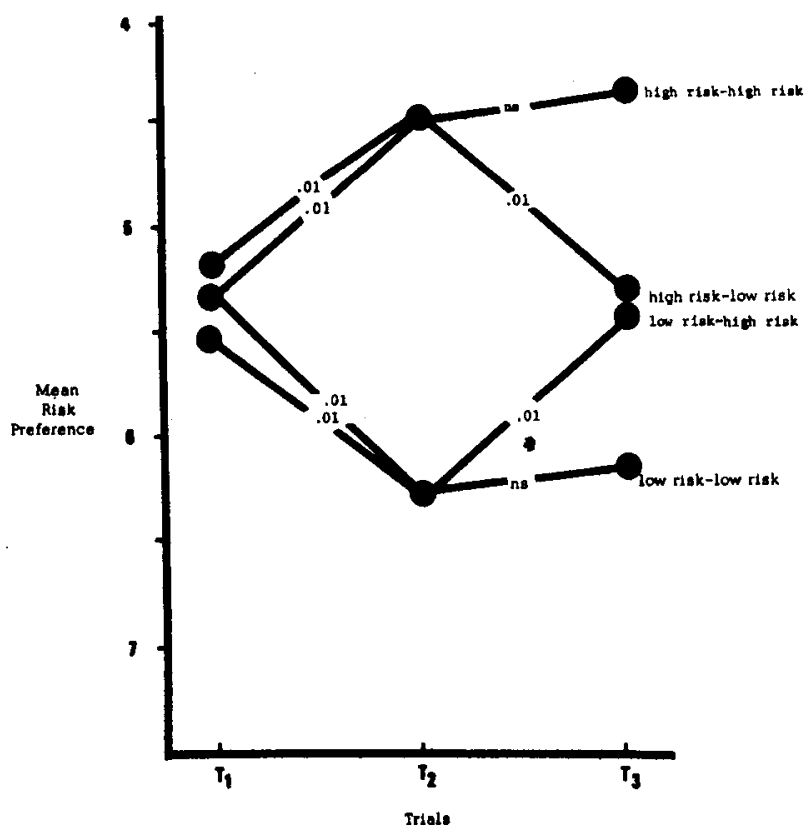

Fig. 2. The means of the Arguments by Trials interaction. Insertion of .01 in the figure indicates significant differences ( $p<.01$ ) between the two connected points using the Newman-Keuls procedure; insertion of ns indicates no significant difference.

much like the 12 items analyzed together.

Post hoc analysis of the Arguments by Trials interaction, shown in Fig. 2, revealed that presentation of new information led to a significant shift toward the position advocated by the information. Presentation of information that was not new resulted in nonsignificant changes. Figures 1 and 2 are nearly identical. This, then, appears to be strong evidence for the relevant arguments hypothesis and negative evidence for the conformity/attitude change hypothesis.

Analysis of the risk-oriented items revealed the same results as in the overall analysis, with only minor changes in the value of the $F$ ratios. Analysis of the two caution-oriented items revealed significant main effects for items $[F(1,64)=5.66, p<.01]$ and for arguments $[F(3,64)=4.84, p<.01]$. The Arguments by Trials interaction was also significant $[F(6,128)=6.80$, $\mathrm{p}<.01]$. Although post hoc differences did not reveal such clear-cut findings for the caution-oriented items as for the risk-oriented items and the overall analysis, the same basic pattern resulted. In half of the conditions where new information was presented, Ss showed a significant shift toward the type of information presented. For the other half of the conditions where new information was presented, the change was in the right direction and close to significant values. When no new information was presented, no shift resulted. The results strongly support the relevant argument hypothesis and refute the predictions of the risk-as-value hypothesis.

\section{CONCLUSIONS}

Before turning to the hypotheses, a general discussion of the data analysis is in order. Different hypotheses were tested by different analyses. However, all of the analyses of variance showed basically the same pattern, even those performed on the individual items. The most consistent finding in these analyses was the significance of the Arguments by Trials interaction. Only in the analysis of one of the items did this interaction not reach significance. This finding, that the arguments would have different effects at different trials, was an inherent assumption in this research and was strongly confirmed.

The risk-as-value hypothesis was tested with two analyses, one using only caution-oriented items and one using only risk-oriented items. Risky arguments did affect the Ss' positions on the caution-oriented items, and cautious arguments did affect the Ss' positions on the risk-oriented items. It might be argued that, when the risky arguments were presented, a value for risk was elicited and that cautious arguments likewise elicited a value for caution, regardless of the orientation of the items. This interpretation does not take into consideration that portion of the risk-as-value hypothesis which assumes that Ss are motivated to compare their responses with the other group members to determine whether, in risk-oriented situations, they are as risky or riskier than most of the other group members. When finding that the other members espouse cautious positions, the risk-as-value hypothesis would certainly predict no shift (Fig. la). The data, however, for items well documented in their risk or caution orientation (Pruitt \& Teger, 1967) does reveal a shift in the direction of the arguments presented when the information is new, whether the arguments favor caution or risk. The risk-as-value hypothesis cannot explain these findings.

The conformity/attitude change hypothesis might counter the present results with an explanation of the data that cites the fact that the other "group members" were in fact not committed to their positions but were merely reading a script. This is a plausible explanation. However, the lack of a second shift in conditions where no new information is presented cannot be explained by the conformity/attitude change hypothesis. (For that matter, it can only be explained with difficulty by the risk-as-value hypothesis.)

The only hypothesis which predicts and explains all of the data in this experiment is the relevant arguments hypothesis. Its prediction was an almost perfect representation of the actual data. New information, whether it supports risk or caution and whether it is given for risk-or caution-oriented items, produces a shift in the direction of the information presented. Information that is not new does not produce a shift. Obviously, these findings are not relevant to other 
hypotheses that have been presented to account for choice shifts. Further research may determine the capabilities of these hypotheses, including the survivor of the present experiment, the relevant arguments hypothesis. The tests reported here, though, at least show da ta strongly in favor of one specific hypothesis. It remains for other possible choice shift explanations to surpass the predictions of this hypothesis in future tests.

\section{REFERENCES}

Brown, R, Social psychology. New York: Free Press, 1965. Chap. 13.

Castore, C. H., Roberts, J. C. Subjective estimates of relative risk and risk taking following a group discussion. Organizational Behavior \& Human Performance, 1972, 7 , 125-143.

Kogan, N., \& Wallach, M. A. Risk taking. New York: Holt, Rinehart, \& Winston, 1964.

Levinger, G., \& Schneider, D. J. Test of "risk as value" hypothesis. Journal of Personality \& Social Psychology, 1969, $11,165-170$

Madaras, G. R., \& Bem, D. J. Risk and conservatism in group decision making. Journal of Experimental Social Psychology, $1968,4,350-366$.

Pruitt, D. G. The "Walter Mitty" effect in individual and group risk taking. Proceedings of the 77th Annual Convention of the American Psychological Association, 1969.

Pruitt, D. G. Choice shifts in group discussion: An introductory review. Journal of Personality \& Social Psychology, 1971, 20, 339-360.

Pruitt, D. G \& Teger, A. I. Is there a shift toward risk? If so, is it a group phenomenon? If so, what causes it? Proceedings of the $75 \mathrm{th}$ Annual Convention of the American Psychological Association, 1967.

Sherif, C. W., Sherif, M., \& Nebergall, R. E. Attitude and attitude change: The social judgment-involvement approach. Philad elphia: Saunders, 1965.

Vinokur, A. A review and the oretical analysis of the effects of group processes up on individual and group decisions involving risk. Psychological Bulletin, 1971, 76, 231-250.

Wallach, M. A., \& Wing, C. W. Is risk a vahe? Journal of Personality \& Social Psychology, 1968, 9, 101107.

Winer, D. J. Statistical principles in experimental design. New York: McGraw-Hill, 1962.

(Received for publication F ebruary 7, 1974 ; revision accepted May $5,1974$. ) 